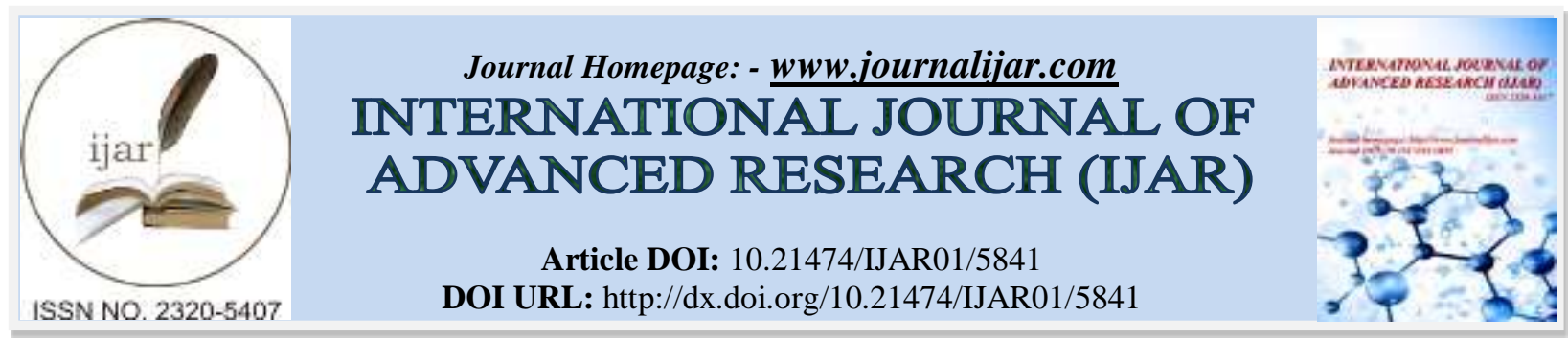

RESEARCH ARTICLE

\title{
EFFECT OF THE ADDITION OF GLASS BOTTLE PARTICLES ON THE MECHANICAL STRENGTHS OF COMPRESSED BLOCKS OF FIRED CLAY AND STABILIZED EARTH.
}

\section{*Gbènondé S. G. MILOHIN ${ }^{1,2}$, Malahimi ANJORIN ${ }^{1}$, Victor S. GBAGUIDI ${ }^{1}$, S. Constant ADISSIN ${ }^{1}$, André DONNOT $^{2}$ and Riad BENELMIR ${ }^{2}$.}

1. Laboratory of Applied Energetics and Mechanics (LEMA), Polytechnic School of Abomey-Calavi / University of Abomey-Calavi, 01 BP. 2009 Cotonou (Benin).

2. Laboratory of Testing and Research on Wood Material (LERMAB), Faculty of Science \& Technology /

University of Lorraine -Bd. des Aiguillettes B.P. 70239 F-54506 Vandoeuvre-lès-Nancy cedex, France.

\section{Manuscript Info}

Manuscript History

Received: 12 September 2017

Final Accepted: 14 October 2017

Published: November 2017

Key words:-

stabilized earth, fired clay, glasses, resistances.

\section{Abstract}

The valorisation of clayey soils in the civil construction and the recycling of the waste are current concerns of several countries like Benin. This study focuses on the development of compressed blocks made of stabilized earth and fired clay containing particles of glass bottles for their use in the building industry. After the characterization of the materials: clayey earth or laterite, clay and crushed glasses; the mechanical strengths of blocks in compression and in traction by flexural test (three-point bending test) were studied for various crushed glass contents ranging from 0 to $60 \%$. In accordance with standard NF P 11-300, the earth soil studied is an $\mathrm{A}_{2 \mathrm{ts}}$ soil and the clay is an $\mathrm{A}_{4}$ soil. The study of mechanical strengths has shown that at 21 days of age, the addition of $10 \%$ of crushed glasses induces a decrease of $10 \%$ of strength in traction by flexural test of the blocks stabilized with cement but a resistance gain of $17 \%$ in compression; the resistances are respectively $1.8 \mathrm{MPa}$ against $2 \mathrm{MPa}$ for the blocks without glasses in traction by three-point flexural test, and $5.3 \mathrm{MPa}$ against $4.5 \mathrm{MPa}$, in compression. In addition, crushed glasses have a positive effect on strengths of fired clay blocks both in traction by flexural test and in compression. The strengths of the blocks with $10 \%$ of crushed glasses are higher than those of the blocks without glasses, and the maximum strength values are obtained at a dosage of $25 \%$ of crushed glasses with increase rates of $13 \%$ and $122 \%$ in traction by flexural test $(8 \mathrm{MPa})$ and in compression (16.6 MPa) respectively.

Copy Right, IJAR, 2017,. All rights reserved.

\section{Introduction:-}

Nowadays, there is the problem of precariousness and high housing prices for people with limited incomes such as those in Benin. Not only is the cost of the first investment for construction high, but the costs of operation and maintenance are higher. This is due to the proliferation of industrial building materials such as steel and cement, for which traditional less expensive materials such as clay or clayey earth are being abandoned. Some conventional construction materials, often imported and whose production needs energy, promote greenhouse gas (GHG) emissions and therefore contribute to global warming. Current concerns then relate to the problems of 
precariousness of the populations ; costs, comfort and durability of buildings but also $\mathrm{CO}_{2}$ emissions favoured by the building sector. To solve these problems, research is increasingly oriented towards the development of new materials that can guarantee acceptable performance without harming the environment while being accessible to people. In Benin, interest is focused on the use and the valorisation of local materials such as clayey earth and compressed clay in the habitat. To solve another environmental problem of waste management, the inclusion of crushed glass waste in these materials is being considered. Glass is one of the most commonly encountered materials in landfills nowadays because it is widely used (Imtiaz, 1991), (Lupien, 2006). Fragile, it generates a lot of residues but has a very long life, allowing it to occupy spaces for periods exceeding 4000 years (Boudlal et al., 2015). The energy used to manufacture glass from raw materials is very important. In addition to the recovery of a part of this energy, the recycling of glass also allows the preservation of nature. Thus, debris of glass (cullet) is added to the raw materials (sand, soda ash, etc.) used for the manufacture of glass. Best of all, glass can be recycled and valorised in Buildings and Public Works (BPW). Various studies showed the possibility of using glass waste, especially in pavement layers for road works (Woodrow, 1993), in concrete (Bazant et al., 2000), (Park et al., 2004), (Idir et al., 2010),(Behim and Ali Boucetta, 2013) and in the manufacture of ceramics (Djomo et al., 2016). But very limited works deal with the valorisation of the particles of glass bottles in blocks made of stabilized earth or fired clay. The problem of waste management of glass bottles is crucial in Benin. The objective of this study is therefore to evaluate the possibility of incorporating crushed glasses in the blocks of fired clay and stabilized earth and then to deduce the optimal formulation for the preparation of these composites for their use in construction.

\section{Materials et methods:- \\ Materials:-}

The clayey soils used in this study were taken in south of Benin ; clay in the commune of the district of SèmèKpodji and clayey sand called "clayey earth" in the district of Abomey-Calavi. The clay samples taken were dried, crushed and sieved ; the clayey earth was also dried and cleared of plant debris. Glasses are waste from unused bottles that end up in landfills. For this purpose, the waste or collected bottles are cleaned and crushed. For the different formulations, the sieving of base materials (clay, clayey earth, crushed glasses) with a $2 \mathrm{~mm}$ sieve was done. The cement used to stabilize the compressed earth blocks is of the CPJ 35 type.

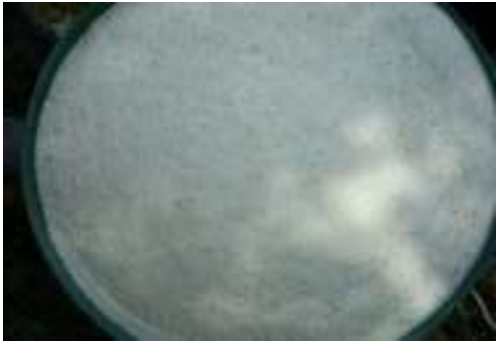

Photo 1: Crushed glasses $<2$ $\mathrm{mm}$

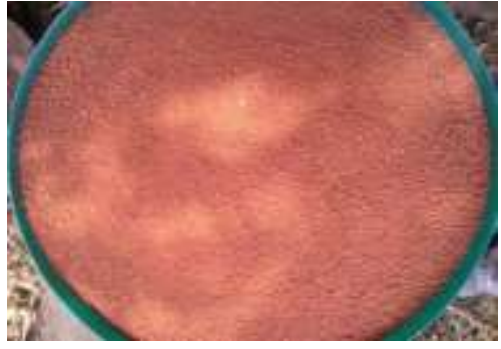

Photo 2: Clayey earth $<2 \mathrm{~mm}$

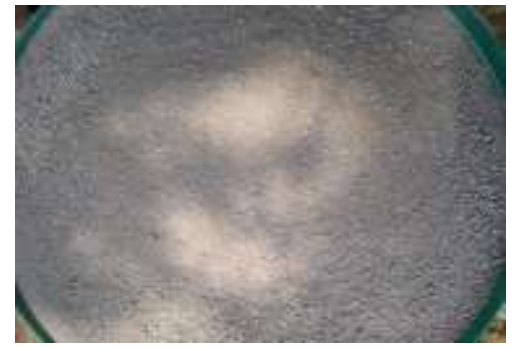

Photo 3: Clay $<2 \mathrm{~mm}$

\section{Methods:-}

\section{Blocks formulation:-}

Two (02) types of blocks incorporating each, proportions of $0 \%, 5 \%, 10 \%, 15 \%, 20 \%, 25 \%, 30 \%, 35 \%, 45 \%, 50 \%$, $55 \%$ and $60 \%$ of crushed glasses (glass particles) by substitution of the basic mixtures are formulated. There are:

- $\quad$ "T" type blocks having as a basic mixture, cement stabilized clayey earth (base1) and

"A" type blocks whose basic mixture consists of clay and clayey earth (base2).

The mixture "base1" is formulated from 10\% of cement and 90\% of the laterite or clayey earth (Avamasse, 2011), (Anjorin et al., 2016); Whatever the dosage of glasses, a constant ratio $\frac{\text { Mass }_{\text {clayey earth }}}{\text { Mass } \text { cement }}=9$ is thus maintained for "T" blocks. For the "A" blocks, the initial study of the proportions of clay and clayey earth enables to define a ratio $\frac{\text { Mass }_{\text {clay }}}{\text { Mass }}$ clayey earth $=4$ that is kept constant also regardless of the dosage in glasses; the mass of clayey earth used corresponds to $20 \%$ of that of the clay (base2). The formulations studied are shown in Table 1 et Table 2 . 
Table 1:- Formulations of the "T" Blocks

\begin{tabular}{|c|c|c|c|c|c|c|c|c|c|c|c|c|c|}
\hline Designation & $\mathrm{T} 0$ & $\mathrm{~T} 5$ & $\mathrm{~T} 10$ & $\mathrm{~T} 15$ & $\mathrm{~T} 20$ & $\mathrm{~T} 25$ & $\mathrm{~T} 30$ & $\mathrm{~T} 35$ & $\mathrm{~T} 40$ & $\mathrm{~T} 45$ & $\mathrm{~T} 50$ & $\mathrm{~T} 55$ & $\mathrm{~T} 60$ \\
\hline $\begin{array}{c}\text { \% of } \\
\text { crushed } \\
\text { glasses }\end{array}$ & 0 & 5 & 10 & 15 & 20 & 25 & 30 & 35 & 40 & 45 & 50 & 55 & 60 \\
\hline $\begin{array}{c}\text { Crushed } \\
\text { glasses } \\
\text { mass (g) }\end{array}$ & 0 & 170 & 340 & 510 & 680 & 850 & 1020 & 1190 & 1360 & 1530 & 1700 & 1870 & 2040 \\
\hline $\begin{array}{c}\text { Clayey } \\
\text { earth mass } \\
\text { (g) }\end{array}$ & 3060 & 2907 & 2754 & 2601 & 2448 & 2295 & 2142 & 1989 & 1836 & 1683 & 1530 & 1377 & 1224 \\
\hline $\begin{array}{c}\text { Cement } \\
\text { mass (g) }\end{array}$ & 340 & 323 & 306 & 289 & 272 & 255 & 238 & 221 & 204 & 187 & 170 & 153 & 136 \\
\hline
\end{tabular}

Table 2:- Formulations of the "A" Blocks

\begin{tabular}{|c|c|c|c|c|c|c|c|c|c|c|c|c|c|}
\hline Designation & A0 & A5 & A10 & A15 & A20 & A25 & A30 & A35 & A40 & A45 & A50 & A55 & A60 \\
\hline $\begin{array}{c}\text { \% of crushed } \\
\text { glasses }\end{array}$ & 0 & 5 & 10 & 15 & 20 & 25 & 30 & 35 & 40 & 45 & 50 & 55 & 60 \\
\hline $\begin{array}{c}\text { Crushed glasses } \\
\text { mass (g }\end{array}$ & 0 & 160 & 320 & 480 & 640 & 800 & 960 & 1120 & 1280 & 1440 & 1600 & 1760 & 1920 \\
\hline Clay mass (g) & 2560 & 2432 & 2304 & 2176 & 2048 & 1920 & 1792 & 1664 & 1536 & 1408 & 1280 & 1152 & 1024 \\
\hline $\begin{array}{c}\text { Clayey earth } \\
\text { mass (g) }\end{array}$ & 640 & 608 & 576 & 544 & 512 & 480 & 448 & 416 & 384 & 352 & 320 & 288 & 256 \\
\hline
\end{tabular}

The mixtures thus formulated, the amount of suitable fresh mortar $(600 \mathrm{~g})$ is introduced into the mold carried by the press for compacting the blocks. After demoulding, a block of dimensions $4 \times 4 \times 16 \mathrm{~cm}^{3}$ is obtained. Three blocks will be used by formulation for the determination of mechanical strengths. The wet cure of the blocks made of clayey earth stabilized with cement " $\mathrm{T}$ " is carried out until different ages for the determination of the mechanical strengths, that is, at 7, 14 and 21 days. The clay blocks are dried under shelter for an average of 14 days. The firing of the blocks is then carried out according to a kinetics which has been determined in advance in a Naberthern electric oven (Graph 1).

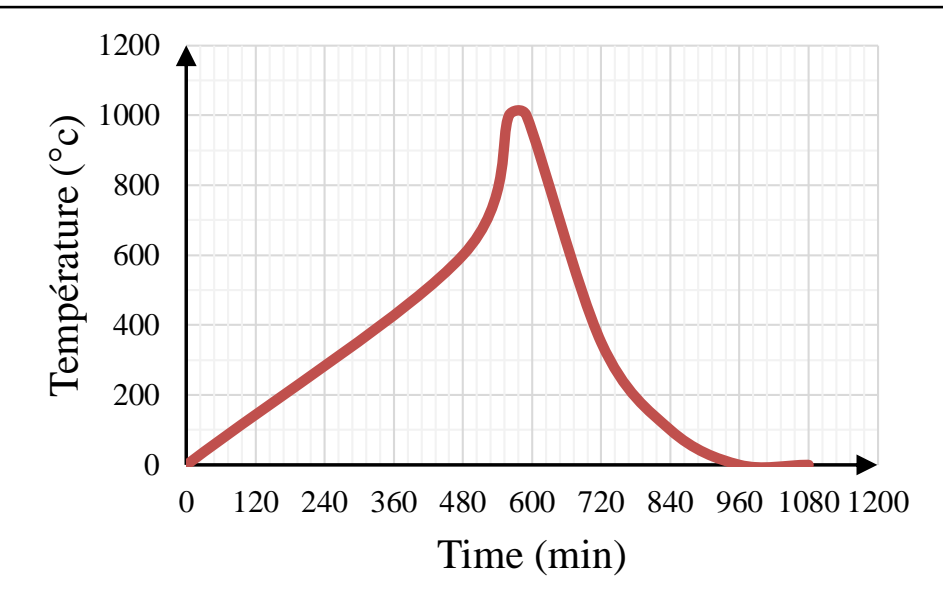

Graph $1:$ Kinetics of fired clay blocks "A" 


\section{Tests performed:-}

First, the characterization of the materials of the study was carried out. In accordance with standard NF EN 933-1 (AFNOR, 2012), the particle size of crushed glasses is determined by dry sieving. For soils (clay and clayey earth), the particle size analysis was done by dry sieving after washing according to standard NF P 94-056 (AFNOR, 1996) and by sedimentation in accordance with NF P 94-057 (AFNOR, 1992). For the "clayey earth" and clay, according to standard NF P94-051 (AFNOR, 1993), the Atterberg's limits were determined, in particular the Liquid limit $\left(\mathrm{W}_{\mathrm{L}}\right)$ test using Cassagrande apparatus and Plastic limit $\left(\mathrm{W}_{\mathrm{P}}\right)$ test on rolled threads. The determination of the density of the solid grains is carried out in accordance with standard NF P 94-054 (AFNOR, 1991) NF P 94-054 (AFNOR, 1991) using a pyknometer. The test for determining the bulk density is also carried out in accordance with standard NF EN 1097-3 (AFNOR, 1998). The dry mass of the aggregates filling a specified container is determined by weighing and the corresponding bulk density is calculated. At the end of the characterization of the basic materials, the influence of crushed glasses on the mechanical strengths of the two types of blocks was appreciated. The determination of the mechanical strengths in traction by three-point flexural test and in compression is therefore performed on these materials of variable percentage of crushed glasses. The blocks are loaded in three-point flexural test and in compression test up to the breaking. The breaking force in each case is used to determine the material strengths. The three-point flexural test is first carried out on specimens of dimensions $4 \times 4 \times 16 \mathrm{~cm}^{3}$ in accordance with the standard NF EN 196-1 (AFNOR, 1995). At break, two fractions of the test sample are obtained; the compression test is then carried out on a surface of $4 \times 4 \mathrm{~cm}^{2}$ of each half-sample. By denoting by $\mathrm{F}_{\mathrm{f}}$ the breaking load of the specimen in flexion, the rupture moment is: $\boldsymbol{F}_{\boldsymbol{f}} \times \boldsymbol{l} / \mathbf{4}$ (Equation 1) and the corresponding bending stress is determined by: $\boldsymbol{R}_{\boldsymbol{f}}=\frac{\mathbf{1 . 5} \boldsymbol{F}_{\boldsymbol{f}} \boldsymbol{l}}{\boldsymbol{b}^{\mathbf{3}}}$ (Equation 2).

By denoting by $\mathrm{F}_{\mathrm{C}}$ the breaking load of the specimen in compression, the compression breaking stress is determined by the formula: $\boldsymbol{R}_{\boldsymbol{c}}(\boldsymbol{M P a})=\frac{\boldsymbol{F}_{\boldsymbol{C}}(\boldsymbol{N})}{\boldsymbol{b}^{2}\left(\boldsymbol{m m}^{2}\right)}$ (Equation 3).

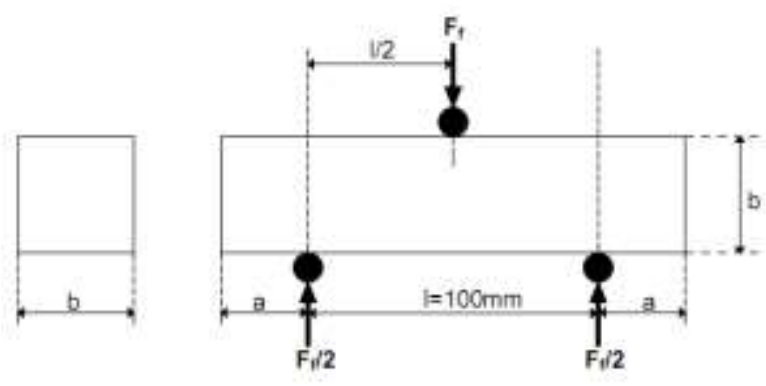

Figure 1:- Device of flexural test (three-point bending test)

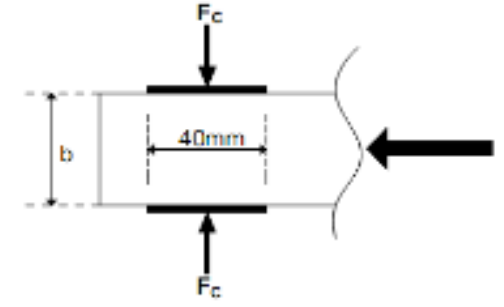

Figure 2:- Device of compression test

\section{Results and discussion:-}

Identification of studied materials:-

Classification of soils according to standard NF P 11-300 and GTR 92:-

These is done using the parameters which are: the particle size distribuion and the Atterberg's limits.

Table 3:- Soil plasticity

\begin{tabular}{|c|c|c|c|}
\hline Materials & Liquid limit $\mathrm{W}_{\mathrm{L}}(\%)$ & Plastic limit $\mathrm{W}_{\mathrm{P}}(\%)$ & Plastic Index $\mathrm{I}_{\mathrm{P}}(\%)$ \\
\hline Clay & 89 & 34 & 55 \\
\hline Clayey earth & 40 & 21 & 19 \\
\hline
\end{tabular}

Clay:-

The clay has a discontinuous particle size distribution with a passing of $93.4 \%$ at $80 \mu \mathrm{m}$ (Graph 2). Its liquid limit is $89 \%$ with a plasticity index of $55 \%$ (Table 3 ). It is therefore an $\mathrm{A}_{4}$ soil. It is then part of the very plastic clay and clayey marl.

\section{Clayey earth or laterite:-}

The clayey earth has a well graded particle size distribution with a passing at $80 \mu \mathrm{m}$ of $51.7 \%$ (Graph 3), a liquid limit of $40 \%$ and a plasticity index equal to $19 \%$ (Table 3), it is a fine clayey sand. Its consistency index is greater than $1.4\left(\mathrm{I}_{\mathrm{C}}>1.4\right)$, so this soil is in a very dry state $\left(\mathrm{A}_{2 \mathrm{ts}}\right)$. 


\section{Classification of soils according to CASAGRANDE's Plasticity Chart: -}

It is done using the liquid limit and the plasticity index. So, with regard to the characteristics of the soils studied (Table 3); Graph 4 indicates that the studied clay is very plastic and the clayey earth is little plastic.

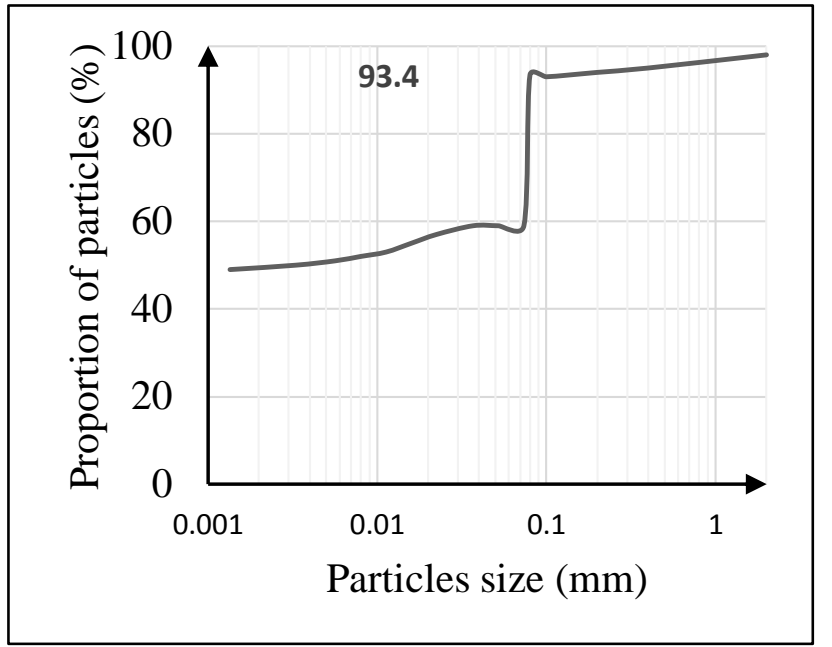

Graph 2: Particle size curve of the clay

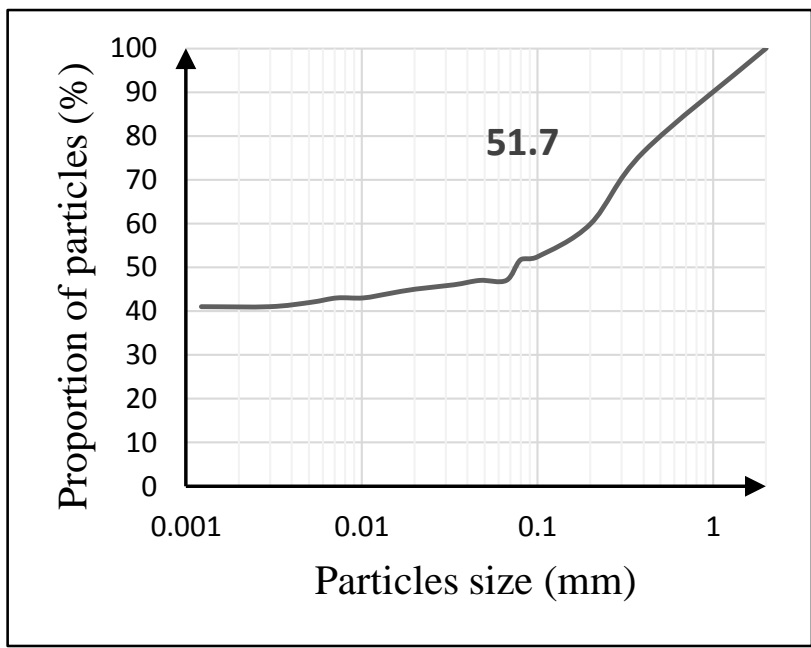

Graph 3: Particle size curve of the clayey earth

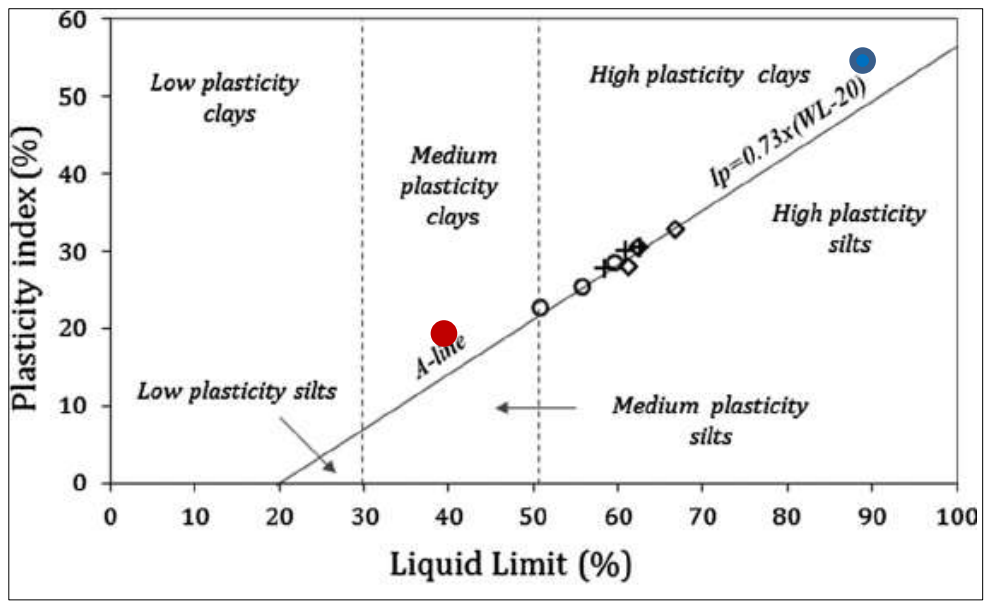

\section{Legend}

Clay

Clayey earth or laterite

\section{Graph 4: CASAGRANDE's Plasticity Chart}

\section{Densities:-}

Table 4 presents the absolute and bulk densities of the materials studied.

Table 4:- Densities of materials

\begin{tabular}{|c|c|c|}
\hline Materials & Absolute densities $\left(\mathrm{g} / \mathrm{cm}^{3}\right)$ & Bulk density $\left(\mathrm{g} / \mathrm{cm}^{3}\right)$ \\
\hline Clay & 2.38 & 1.22 \\
\hline Clayey earth & 2.70 & 1.15 \\
\hline Crushed glasses & 2.54 & 1.51 \\
\hline
\end{tabular}

\section{Glasses crushed:-}

Graph 5 shows the particle size distribution curve of the crushed glasses. This material has a well graded particle size distribution with a percentage of fines as 1.98 . 


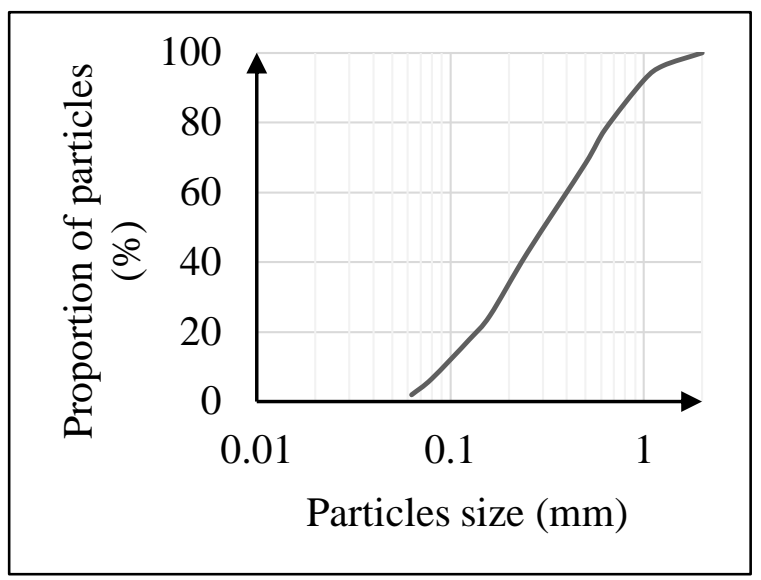

Graph 5 : Particle size curve distribution of the crushed glasses

\section{Moisture content of mortars for making blocks:-}

The previously dried materials, the water contents of the mixtures are determined from the amount of mixing water required to obtain the desired consistency for the mixture intended for making the different test pieces to be tested.

\section{Cement stabilized blocks « $T$ »:-}

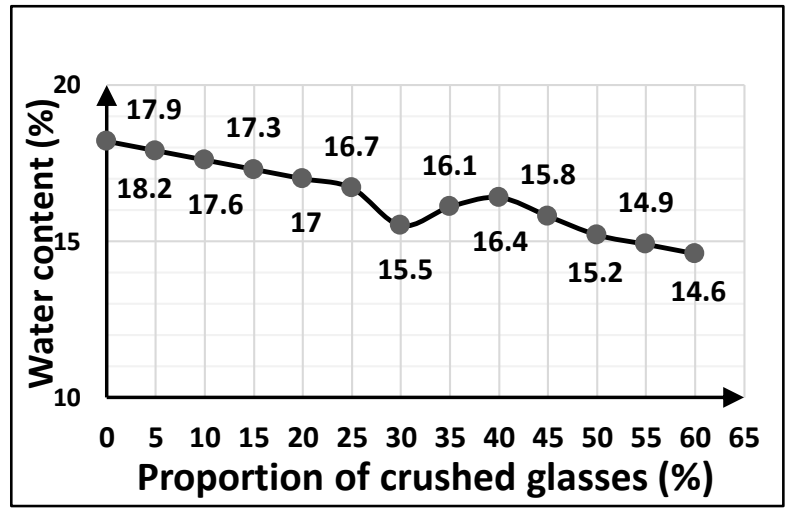

Graph 6: Influence of glasses on the water content of the blocks « $T$ »

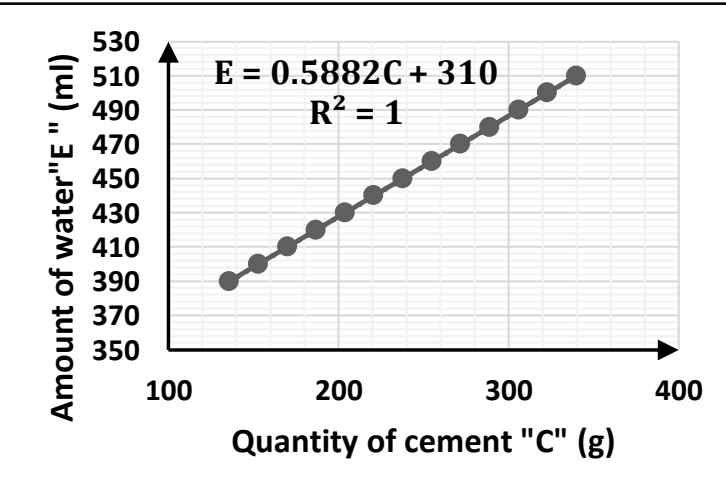

Graph 7: Evolution of the quantity of water according to the cement dosage

Graph 6 shows the evolution of the water content of the "T" mixtures as a function of the crushed glass dosage. It can be observed that the water content of the fresh mortar evolves inversely with the addition of glass. Indeed, the total mass of the dry mixture being kept constant regardless of the dosage, the increase in the proportion of glasses leads to the reduction of the amount of cement in the total mixture. The amount of cement being reduced, the mixing 
water required for its hydration is also reduced. The crushed glasses do not absorb the water of the mixture as; they are waterproof. It is then the amount of cement in the mixture that defines the proportion of appropriate mixing water.

Graph 7 shows the amount of mixing water of the different mixtures depending on the amount of cement used. It is observed that the variation of the quantity of water of the mixtures is a function of the cement mass introduced and results in a linear relation which is defined as: $E=0.5882 C+310$ (Equation 4).

Where $\mathrm{E}$ and $\mathrm{C}$ are expressed in grams ( $\mathrm{g}$ ) and denote respectively the amount of mixing water and the quantity of cement of the mixture.

Fired clay blocks « $\mathbf{A} »:-$

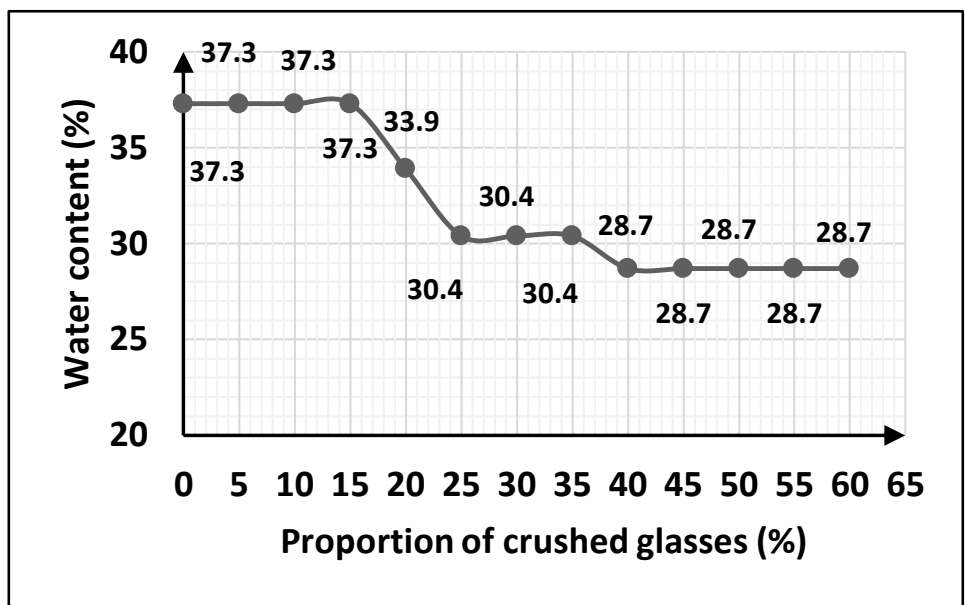

Graph 8: Water content of mixtures "A" for the preparation of cooked blocks

Graph 8 shows the evolution of the water content of mixtures "A" as a function of the crushed glass dosage. It is observed that the water content of the mixtures before firing as a function of the increase of the crushed glass dosage is constant between 0 and 15\%, decreases between 15 and $40 \%$ and becomes constant beyond $40 \%$. The amount of water required to moisten the various mixtures thus decreases with the increase of the crushed glass dosage. The addition of crushed glasses contributes to the reduction of the intergranular porosity of the mixtures and consequently to the absorption of water in the medium. Moreover, the increase of the crushed glass content induces the reduction of the amount of clay in the mixture (total dry mass of the mixture constant) and consequently its sensitivity to water due to the fine elements contained in the clay. A correction of the particle size distribution therefore occurs by adding crushed glass grains to the mixtures. The plasticity of the clay is then reduced. The crushed glasses would therefore act as "degreasers".

The mechanical resistance of the blocks:-

Traction strengths of the compressed earth blocks stabilized with cement "T":-

Graph 9 shows the influence of crushed glass dosage on tensile strengths by three-point bending of earth blocks stabilized with cement. 


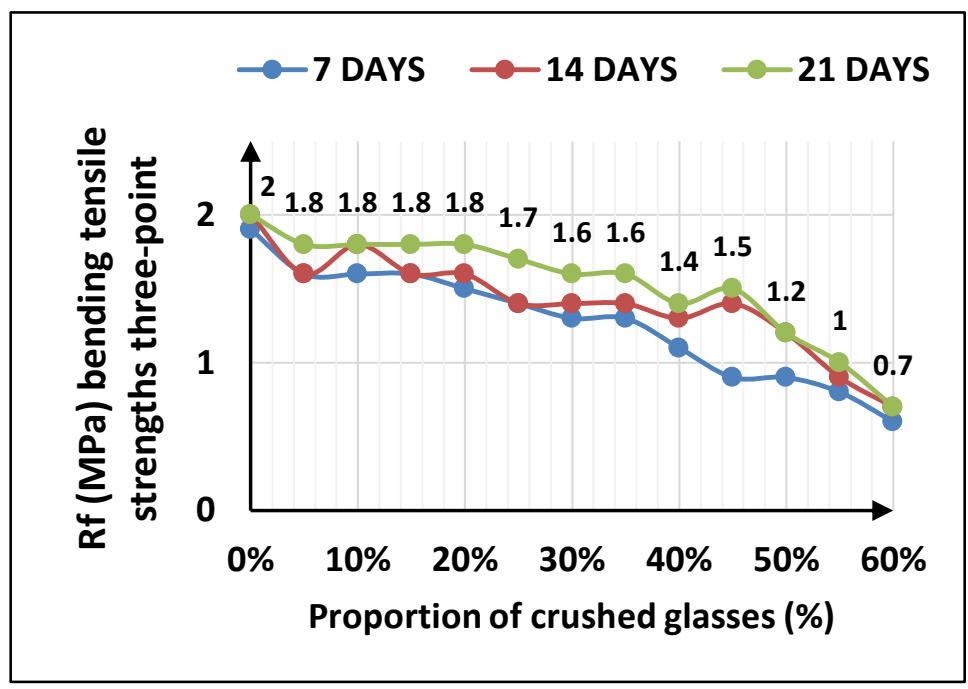

Graph 9: Bending tensile strengths of "T" blocks as a function of crushed glass dosage

Whatever the age considered, it is found that the higher the dosage of crushed glasses, the less the blocks resist bending. At 10\% dosage of crushed glasses, it is observed that the maximum resistance at 21 days of age is reached as early as the 14th day. However, the resistances obtained are all lower than those of the reference blocks, block without the addition of crushed glass $(0 \%)$. With the incorporation of crushed glasses (5 to $60 \%$ ), flexural tensile strengths decreased from $10 \%$ to $65 \%$ as compared to those of the reference blocks $(0 \%)$. The glass therefore has a negative effect on the bending tensile strength of the compressed earth blocks stabilized with cement. Indeed, the addition of crushed glasses to the mixtures reduces the amount of clay that connects the grains together; the internal cohesion forces of the material are reduced. This explains the low resistance values obtained with the increase of the glass dosage.

Compression strengths of the compressed earth blocks stabilized with cement "T":-

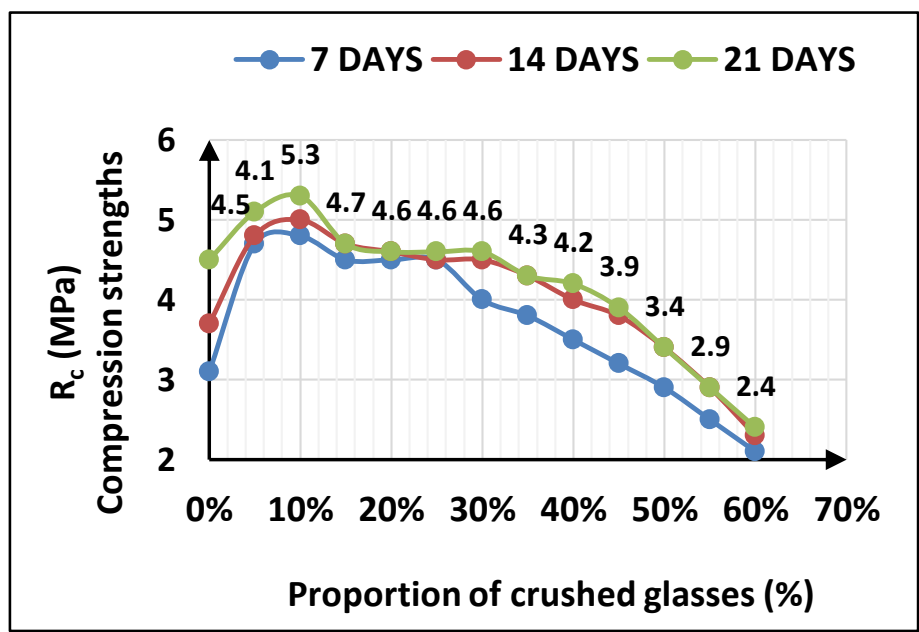

Graph 10: Resistances in compression of the "T" blocks as a function of the crushed glass dosage

The compressive strengths are observed for the " $\mathrm{T}$ " blocks on Graph 10. We find that compressive strength increases with age. Between 0 and $30 \%$, whatever the age considered, the resistances of the blocks with crushed glasses are all higher than that of the reference blocks without crushed glass (0\%). The maximum resistance at 21 days of age, 
5.3 MPa, is obtained at the dosage of $10 \%$ crushed glasses against 4.5 MPa for samples without crushed glasses $(0 \%)$. Beyond $30 \%$, the addition of glasses no longer contributes to the compression strength gain in comparison with the control blocks (blocks without crushed glasses). We also note that: whatever the age and whatever the glass dosage, the maximum and optimal compression resistance is obtained at $10 \%$ of dosage; "T10 block". The incorporation of $10 \%$ of crushed glass in the blocks not only contributes to the increase of $17 \%$ in compressive strength at 21 days as compared to blocks without glasses (0\%) but also, leads to the reduction of $1 \%$ of the cement quantity used since the formulation giving the blocks "T10" showing the optimal resistances is: $10 \%$ crushed glasses $+81 \%$ clayey earth $+9 \%$ cement.

By combining the recorded mechanical performances, we may say that in proportions varying from $0 \%$ to $20 \%$ (possibly 25\%) relative to the total mass of the dry mixture, the crushed glasses could be incorporated in the clayey earth stabilized with cement while respecting the previously defined proportions for the manufacture of the compressed earth blocks stabilized with cement for use in the building sector. A thorough characterization of the formulated composites would enable the definition of specific performance criteria for their manufacture.

The fired clay bricks "A":-

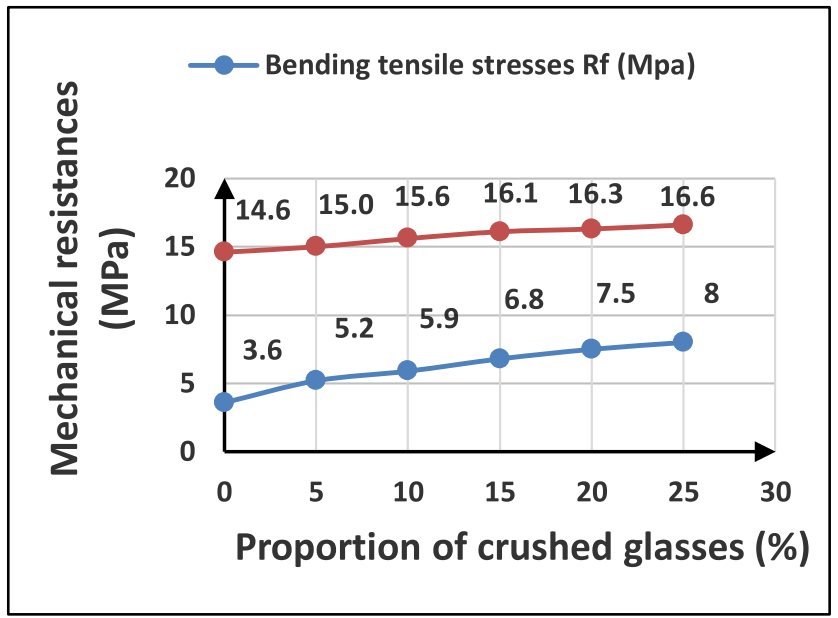

Graph 11: Mechanical strengths of blocks "A" according to the dosage of crushed glasses

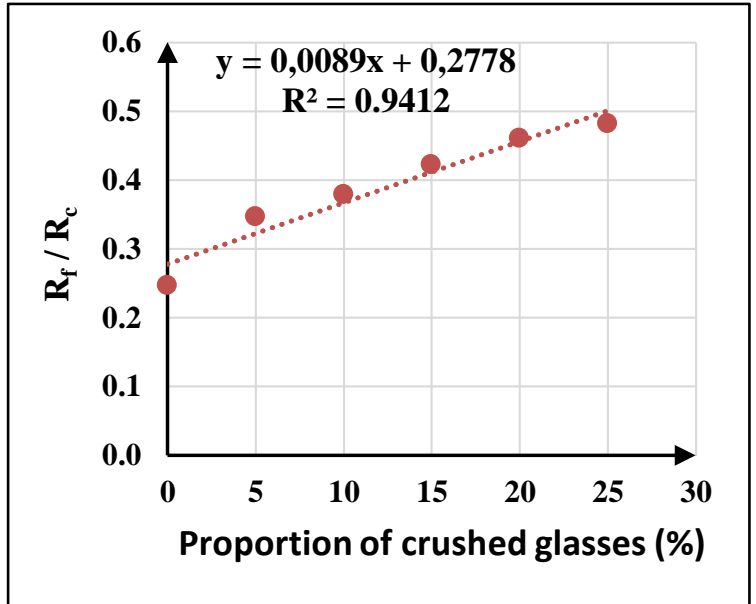

Graph 12: Variation of mechanical strengths according to the dosage of crushed glasses

The results presented here are limited to the dosages of 0 to $25 \%$ of crushed glasses because we note, for the same firing kinetics, substantial deformations (swelling, cracking) of the blocks having crushed glass content greater than $25 \%$. The study of the appropriate firing kinetics for the blocks containing more than $25 \%$ of crushed glasses will then be the subject of further work. The results of the mechanical tests (three-point bending test and compression test) performed on blocks with less than $25 \%$ of crushed glasses are presented in Graph 11.

In compression and traction by bending, the behaviour of the blocks is similar. It is observed that the mechanical strengths increase considerably according to the dosage of crushed glasses. At $10 \%$ addition, the resistances of the fired clay blocks which are 15.6 MPa in compression and 5.9 MPa in tensile by bending, are greater than those of reference blocks ( $0 \%$ addition of crushed glasses) and of stabilized blocks with cement for the same dosage. For an addition to $25 \%$ crushed glasses, the maximum resistance values of these materials are obtained; it is observed an increase rate of $13 \%$ and $122 \%$ in the tensile strength by bending and in compression respectively as compared to the control blocks ( $0 \%$ of crushed glasses). Incorporation up to $25 \%$ by mass of ground glasses with respect to the total mass of dry mixture significantly improves the performance of the fired clay blocks. In fact, the calcined glass melts around $1000^{\circ} \mathrm{C}$ and the agglomeration of the soil particles and, once the bricks are cooled, it makes the latter more solid. The proportion of the added crushed glasses must be controlled because remember that beyond $25 \%$ of crushed glasses, considerable deformations are observed on the blocks. This added material therefore positively influences the mechanical performance of the material when it is incorporated in well-defined proportions. The optimal formulation of the composite for the fired clay bricks ("A25" blocks) is thus defined as: $25 \%$ crushed glasses $+15 \%$ clayey earth $+60 \%$ clay. The variation of the flexural tensile strength $R_{f}$ with respect to those of 
compression $\mathrm{R}_{\mathrm{c}}$ of the fired clay blocks, as a function of crushed glasses dosage (Graph 12) results in the relationship defined as: $R_{f}=(0.0089 d+0.2778) R_{C}$ (Equation 5).

Where $R_{f}$ : Tensile strength by flexural test (MPa); $R_{c}$ : Resistance in compression (MPa) and $d: 100 \times($ proportion of crushed glasses $(\%))$.

\section{Conclusion:-}

The present work devoted to the study of the influence of the addition of crushed glasses on the mechanical performance of compressed stabilized earth blocks and fired clay blocks, allowed us to classify the clay used as $\mathrm{A}_{4}$ soil and the clayey earth as $A_{2 \text { ts }}$ according to the standard NF P 11-300. Incorporation of $10 \%$ crushed glasses into clayey earth stabilized with cement showed a $17 \%$ increase in compressive strength and a $10 \%$ decrease in flexural tensile strength. For the same dosage, the fired clay blocks have better strengths, and the maximum and optimum performance are recorded at the dosage of $25 \%$ where increases of $13 \%$ in flexural tensile and $122 \%$ in compression are recorded as compared to the reference blocks ( $0 \%$ crushed glasses). The blocks of "T10" and "A25" have therefore proved more interesting by their optimal performance. Proximity materials such as the "clayey earth " and clay, as well as aggregates of non-reused glass bottle residues, can be valorized as compressed stabilized blocks for their use in the construction of modern homes at lower cost.

\section{References:-}

1. AFNOR. (1991). NF P94-054 Sols: reconnaissance et essais. Détermination de la masse volumique des particules solides des sols - Méthode du pycnomètre à eau.

2. AFNOR. (1992). NF P94-057 Sols: reconnaissance et essais. Analyse Granulométrique des sols - Méthode par sédimentation.

3. AFNOR. (1993). NF P94-051 Sols: reconnaissance et essais. Détermination des limites d'Atterberg - Limite de liquidité à la coupelle - Limite de plasticité au rouleau.

4. AFNOR. (1995). NF EN 196-1 Méthodes d'essai des ciments - Partie 1: Détermination des résistances mécaniques.

5. AFNOR. (1996). NF P94-056 Sols: reconnaissance et essais. Analyse Granulométrique des sols - Méthode par tamisage à sec après lavage.

6. AFNOR. (1998). NF EN 1097-3 Essais pour déterminer les caractéristiques mécaniques et physiques des granulats Partie 3: Méthode pour la détermination de la masse volumique en vrac et de la porosité intergranulaire.

7. AFNOR. (2012). NF EN 933-1 Essais pour déterminer les caractéristiques géométriques des granulats Partie 1 : Détermination de la granularité - Analyse granulométrique par tamisage.

8. Anjorin, M., Toukourou, C. A., Houngan, A. C., Awanto, C., Madougou, L. (2016). Characterization of Stabilized Earth Blocks with Incorporation of Cement Expanded Polystyrene for Use in Buildings. Journal of Civil Engineering and Architecture, 10(1). https://doi.org/10.17265/1934-7359/2016.01.007

9. Avamasse, S. (2011). Caractérisation thermomécanique des blocs de terre comprimée (BTC) avec ajout de sciure de bois (Mémoire de fin de formation pour l'obtention du diplôme d'ingénieur de conception en génie civil) (p. 192). Bénin: Ecole Polytechnique de l'Université d'Abomey-Calavi.

10. Bazant, Z. P., Zi, G., Meyer, C. (2000). Fracture Mechanics of ASR in Concretes with Waste Glass Particles of Different Sizes. Journal of Engineering Mechanics, 126(3), 226-232. https://doi.org/10.1061/(ASCE)07339399(2000)126:3(226)

11. Behim, M., Ali Boucetta, T. (2013). Valorisation du verre à bouteille comme addition fine dans les bétons autoplaçants. Déchets, Sciences et Techniques, (65). https://doi.org/10.4267/dechets-sciences-techniques.932

12. Boudlal, O., Khattaoui, M., Djemai, M., Medani, M. (2015). Etude du comportement mécanique d'un mélange de granulats naturels et du verre pour une utilisation dans la construction routière (S25). In 22ème Congrès Français de Mécanique, 24 au 28 août 2015, Lyon, France (FR). Retrieved from http://documents.irevues.inist.fr/handle/2042/57486

13. Djomo, S. A., Kouakou, H. C., Kouadio, C. K., Boffoue, O. M., Emeruwa, E. (2016). Détermination d'une formulation de carreaux monocouche avec une incorporation de tessons de bouteille de verre. International Journal of Innovation and Applied Studies, 17(1), 269-274.

14. Idir, R., Cyr, M., Tagnit-Hamou, A. (2010). Peut-on valoriser massivement le verre dans les bétons ? Etude des propriétés des bétons de verre., 16(5/6), 70-77. 
15. Imtiaz, A. (1991). Use of Waste Materials in Highway Construction (Joint Highway Research Project Final Report No. FHWA/IN/JHRP-91/3). School of civil engineering indiana department of transportation. Retrieved from http://docs.lib.purdue.edu/cgi/viewcontent.cgi?article $=1771 \&$ context $=$ jtrp

16. Lupien, C. (2006). Projet pilote de valorisation du verre récupéré (non conforme pour le conditionnement) dans la construction de chaussées (Rapport présenté à RECYC-QUÉBEC) (p. 24). Retrieved from https://www.recycquebec.gouv.qc.ca/sites/default/files/documents/projet-pilote-valorisation-verre-recup.pdf

17. Park, S. B., Lee, B. C., Kim, J. H. (2004). Studies on mechanical properties of concrete containing waste glass aggregate. Cement and Concrete Research, 34(12), 2181-2189. https://doi.org/10.1016/j.cemconres.2004.02.006

18. Woodrow, J. H. (1993). Use of waste glass in highway construction (Update-1992) (Technical assistance report) (p. 26). Charlottesville, Virginia: Virginia Transportation Research Council. 